\title{
FORMAÇÃO DO PREÇO DE VENDA DO MORANGO ORGÂNICO A PARTIR DOS CUSTOS DE PRODUÇÃO
}

\author{
Marlowa Zachow ${ }^{1}$ \\ Marinês Luiza Guerra Dotto ${ }^{2}$ \\ Lígia Fiedler $^{3}$ \\ Odacir Miguel Tagliapietra ${ }^{4}$ \\ Geysler Rogis Flor Bertolini ${ }^{5}$
}

ZACHOW, M.; DOTTO, M. L. G.; FIEDLER, L.; TAGLIAPIETRA, O. M.; BERTOLINI, G. R. F. Formação do preço de venda do morango orgânico a partir dos custos de produção. Rev. Ciênc. Empres. UNIPAR, Umuarama, v. 19, n. 2, p. 243-256, jul./dez. 2018.

RESUMO: Através de revisão de literatura acerca de custos de produção e formação de preço de venda, buscou-se no trabalho o cálculo do preço através do mark-up para a produção de morangos orgânicos. Utilizando-se um estudo de caso em propriedade em Sede Alvorada/ PR, percebeu-se que é possível utilizar os conceitos de contabilidade de custos aliados a contabilidade rural para calcular o custo de produção e o preço de venda, fazendo pequenas adaptações devido às particularidades da agricultura familiar. Com o cálculo do preço chegou-se à conclusão que a atividade é rentável para a produtora, e que o preço encontrado é mais baixo do que se comprando o produto de outras regiões. A produção local, além de ter uma ótima qualidade, possibilita a venda sem os custos de transporte, alavancando o consumo desse produto.

PALAVRAS-CHAVE: Orgânicos; Agricultura familiar; Custos; Preço de venda; Markup.

DOI: $10.25110 /$ receu.v19i2.6880

${ }^{1}$ Doutoranda em Desenvolvimento Rural Sustentável na Universidade Estadual do Oeste do Paraná (UNIOESTE), Professora do Centro de Ciências Sociais Aplicadas na Universidade Estadual do Oeste do Paraná (UNIOESTE), marlowaz@hotmail.com.

${ }^{2}$ Doutoranda em Desenvolvimento Rural Sustentável na Universidade Estadual do Oeste do Paraná (UNIOESTE), Professora do Centro de Ciências Sociais Aplicadas na Universidade Estadual do Oeste do Paraná (UNIOESTE), ml.dotto@terra.com.br

${ }^{3}$ Mestre em Administração pela Universidade Federal do Paraná (UFPR), Professora do Centro de Ciências Sociais Aplicadas na Universidade Estadual do Oeste do Paraná (UNIOESTE), ligiaf.adm@ gmail.com

${ }^{4}$ Doutorando em Desenvolvimento Rural Sustentável na Universidade Estadual do Oeste do Paraná (UNIOESTE), Professor do Centro de Ciências Sociais Aplicadas na Universidade Estadual do Oeste do Paraná (UNIOESTE), odacirtagliapietra@gmail.com

${ }^{5}$ Doutor em Engenharia de Produção pela Universidade Federal de Santa Catarina (UFSC), Professor do Centro de Ciências Sociais Aplicadas na Universidade Estadual do Oeste do Paraná (UNIOESTE), geysler_rogis@yahoo.com.br 


\title{
PRICE FORMATION FOR THE SALE OF ORGANIC STRAWBERRIES FROM THE PRODUCTION COSTS
}

\begin{abstract}
Through a literature review on the production costs and sale price formation, this study aimed at calculating the price through markup for the production of organic strawberries. Using a case study at the property located at Sede Alvorada in the state of Paraná, it could be observed that it is possible to use the concepts of cost accounting combined with rural accounting to calculate the cost of production, making small adjustments due to the specificities of family farming. With the price calculation, it was observed that the activity is profitable for the producer, and that the price found is lower than if buying the product from other regions. The local production, in addition to having a great quality, makes it possible to be sold without transportation costs, leveraging the consumption of this produce.

KEY WORDS: Organic; Family agriculture; Costs; Sale price; Markup.

\section{FORMACIÓN DEL PRECIO DE VENTA DE LA MUJER ORGÁNICAA PARTIR DE LOS COSTES DE PRODUCCIÓN}

RESUMEN: A través de revisión de literatura acerca de costos de producción y formación de precio de venta, se buscó en el trabajo el cálculo del precio a través del markup para la producción de fresas orgánicas. Se utilizó un estudio de caso en propiedad en Sede Alvorada / PR, se percibió que es posible utilizar los conceptos de contabilidad de costos aliados a la contabilidad rural para calcular el costo de producción, haciendo pequeñas adaptaciones debido a las particularidades de la agricultura familiar. Con el cálculo del precio se llegó a la conclusión que la actividad es rentable para la productora, y que el precio encontrado es más bajo que comprando el producto de otras regiones. La producción local, además de tener una óptima calidad, posibilita la venta sin los gastos de transporte, apalancando el consumo de ese producto.

PALABRAS CLAVE: Orgánicos; Agricultura familiar; Costos; Precio de venta; margen de beneficio.

\section{INTRODUÇÃO}

A agricultura familiar precisa sempre se reinventar para oferecer produtos diferenciados e de qualidade. A produção de orgânicos tem se mostrado uma opção viável do ponto de vista econômico e ambiental. Alguns consumidores têm mostrado que estão dispostos a pagar mais para consumir um produto que tenha melhor qualidade, sem agrotóxicos e não prejudique a saúde.

Aliado ao desejo do consumidor, os produtores também procuram alter- 
nativas que atendam não somente o lado financeiro, mas permita que eles vivam em harmonia com a natureza. A produção de orgânicos prima pela ausência de aditivos químicos ou agrotóxicos, o que protege não somente a saúde do produtor e do consumidor, mas também poupa o meio ambiente.

A agricultura familiar é explorada por pequenos agricultores e são eles que aceitam o desafio do cultivo de alimentos orgânicos, com muitas barreiras enfrentadas, entre elas está a maneira de produção, a comprovação da origem dos produtos orgânicos que normalmente são produtos de ciclos curtos e ainda precisam calcular os custos e chegar no preço final do produto para levar até o consumidor. Porém, a agricultura familiar oferece alternativas para diversificar as atividades e melhorar a renda da família.

É preciso identificar os custos corretamente por meio de um demonstrativo com capacidade de evidenciar esses valores para os produtores, gerar informações sobre a cultura de alimentos orgânicos e tomar decisões sobre o preço final de venda. Diante dos fatos e a relevância do assunto muitos produtores apresentam dificuldades para analisar os procedimentos que devem seguir para elaboração dos custos. Neste contexto este estudo busca responder ao seguinte questionamento: Quais as informações são relevantes para calcular o custo de produção e preço de venda da cultura de morangos orgânicos?

Para produção e venda de qualquer produto é necessário conhecer os custos de produção, para que seja possível formar um preço adequado. Na produção agrícola são aproveitados alguns conceitos da contabilidade de custos e alguns da contabilidade rural. Algumas características da produção familiar também devem ser levadas em consideração para apuração desse custo, como por exemplo a ausência de salários da mão de obra da família.

Diante desse contexto, esse trabalho tem como objetivo geral simular a formação de preço de venda do morango orgânico, a partir dos custos de produção, em uma propriedade de agricultura familiar no município de Sede Alvorada/ PR.

\section{REFERENCIAL TEÓRICO}

\subsection{Produção de orgânicos}

O processo atual de produção e consumo de produtos orgânicos evolui conforme a mudança de hábitos da população, porém os alimentos orgânicos não são prioridade nas refeições diárias dos brasileiros, por problemas quanto à aparência dos produtos, preço elevado, pouca oferta e outros fatores que envolvem a produção de alimentos orgânicos.

De acordo com Fonseca e Wilkinson (2002, p. 249): 
A definição de agricultura orgânica ainda apresenta alguns problemas, a complexidade, flexibilidade, mas de modo geral é entendida como sistema produtivo e agroextrativista que evita o uso de agroquímicos e reguladores de crescimento, tanto na alimentação dos animais como na fertilização dos solos e no combate a pragas e a doenças. Ao mesmo tempo, exige uma gama de práticas para assegurar ao sistema a sustentabilidade de sua capacidade produtiva.

Para Bittencourt (2002), os consumidores de alimentos estão sendo exigentes, na busca por produtos diferenciados que proporcionam benefícios principalmente para a saúde, procuram por produtos orgânicos. Na produção de orgânicos não são utilizados agrotóxicos e nem estimulantes que alterem a forma natural do produto. Essa técnica já vem sendo utilizada por alguns agricultores que despertaram para uma produção consciente, que também está relacionada com a proteção ambiental.

Cresce a procura pelos produtos orgânicos e pela sua qualidade, embora o processo de certificação seja muito lento e o ciclo de produção é muito rápido, os consumidores questionam quanto à procedência e o manejo dos alimentos. É importante saber de onde vêm os produtos, neste contexto, existe a certificação participativa, que fiscaliza todo o processo e expede uma autorização para comercialização dos produtos, especialmente em feiras livres ou circuitos curtos.

Em geral os produtos orgânicos têm um valor agregado maior, sendo que alguns consumidores estão dispostos a pagar mais para obter um produto livre de agrotóxicos. Bittencourt (2002, p.89) afirma que: "Os produtos orgânicos têm preços superiores aos dos produtos convencionais e o aumento da demanda desperta o interesse dos grandes produtores, que enxergam a produção orgânica como ótima alternativa para ampliação da renda".

A produção de orgânicos pode ser uma alternativa para a agricultura familiar, em um momento que este seguimento vem enfrentando desafios e dificuldades para atender as exigências para produção e venda. Orsi (2002, p.157) afirma que "Foi a partir da década de 1950 que se acentuaram as dificuldades de comercialização direta dos produtos processados nas pequenas agroindústrias rurais. Isto se deu principalmente por causa da implantação da legislação sanitária federal de inspeção de alimentos". Em relação às mudanças necessárias nas práticas da agricultura familiar Orsi (2002, p.158) entende que:

[...] uma das primeiras propostas foi promover mudanças e aproveitar parte dos sistemas tradicionais da agricultura de economia familiar para desencadear novas práticas de produção e desenvolver produtos com características 
próprias a esta agricultura. Isso veio ao encontro da opção de consumo da sociedade urbana, que passou a valorizar cada vez mais o produto alimentar com características diferenciadas, como naturais-orgânicos.

Orsi (2002) acredita ainda que para satisfazer tanto as necessidades dos consumidores quanto colaborar com a permanência da agricultura familiar no mercado foi necessário estreitar o caminho entre produtores e consumidores. Com esse objetivo foram realizadas algumas iniciativas de cunho científico e tecnológico. A partir dessas iniciativas surgiram tecnologias para produção agroecológica ou orgânica.

\subsection{Custos de produção}

Existem diversos gastos que são necessários para a produção de algo. Existe uma diferença nas nomenclaturas desses gastos, que ajuda a identificar a natureza do gasto, subsidiando decisões a respeito dele. A primeira diferenciação existente é entre o conceito de custo e de despesa. Os custos são os gastos necessários para fabricação de um produto, enquanto as despesas são os gastos referentes à administração, vendas e financiamentos (MARTINS, 2003).

Os custos podem ser classificados em diretos e indiretos. Os custos diretos são aqueles que têm direta identificação com o produto. Geralmente, esses custos têm uma medida de consumo que deve ser usada para apropriação, como quilogramas de matéria-prima consumida e horas de mão de obra, por exemplo. Já os custos indiretos são os que não possuem uma medida objetiva para apropriação ao produto. Esses custos precisam de rateio para que sejam alocados. São exemplos de custos indiretos o aluguel e salários de supervisores, conforme Martins (2003).

Segundo Martins (2003), além da classificação dos custos em diretos e indiretos, ainda pode-se classificá-los em fixos e variáveis. Os custos variáveis são aqueles que variam em função da produção e os custos fixos são aqueles que permanecem iguais, independente do volume de produção no período. Essa classificação permite diversas análises, pois o custo fixo é diluído nas unidades produzidas, ou seja, quanto mais se fabrica um produto, menor o custo fixo unitário do mesmo.

As despesas também podem seguir a classificação de variáveis e fixas, pois algumas despesas são fixas no período e outras podem variar em função da quantidade vendida, por exemplo, comissões e impostos sobre vendas são exemplos de despesas variáveis (MARTINS, 2003).

\subsection{Custos de produção agrícola}

Para entender melhor os custos de produção agrícola, é necessário en- 
tender a distinção entre cultura temporária e cultura permanente. As culturas permanentes são aquelas que proporcionam mais que uma colheita, e as culturas temporárias são aquelas de período de vida curto, sujeitas ao replantio após a colheita (MARION, 2012).

Os custos de produção agrícola seguem os mesmos critérios de custo utilizados para a produção industrial, respeitando-se as devidas especificidades. Para isso, é necessária a identificação correta dos gastos. Os gastos podem ser divididos inicialmente em investimentos, despesas e custos. Os investimentos são bens que comporão o ativo da empresa, rural e produzirão resultados futuros. Os custos são os gastos que são aplicados na produção rural. As despesas são os gastos não utilizados na produção (CREPALDI, 2012).

Os custos diretos podem ser apropriados diretamente aos produtos, sem necessidade de rateios. Na produção agrícola os custos diretos geralmente encontrados são: insumos, mão de obra, material de embalagem, depreciação de máquinas agrícolas e energia elétrica (CREPALDI, 2012).

Os custos indiretos não conseguem ser apropriados diretamente aos produtos, necessitando de algum tipo de cálculo ou rateio. São exemplos de custos indiretos na produção agrícola: depreciação de equipamentos utilizados na produção de mais de um produto, salários de chefes e supervisores, impostos e taxas da propriedade rural (CREPALDI, 2012).

Os custos fixos são aqueles que o total não varia conforme o volume produzido. Já os custos variáveis aumentam conforme a quantidade produzida aumenta (CREPALDI, 2012). Na atividade agrícola são exemplos de custos fixos o salário dos gestores da fazenda e arrendamento. Os custos variáveis existentes são sementes, defensivos, mão de obra temporária e outros.

\subsection{Formação do preço de venda a partir do custo}

O preço de venda pode ser definido como o valor pelo qual um produto ou serviço pode ser trocado no mercado. Este conceito pode ser avaliado por duas óticas: do consumidor e do vendedor. Para o consumidor, o preço corresponde ao valor pelo qual está disposto a pagar pelo produto ou serviço e para o vendedor, o preço de venda é o valor pelo qual aceita trocar sua produção ou serviço. Dessa forma, na formação de preços, o produtor rural deve estudar fatores internos e externos que influenciam nos preços de venda, buscando conciliar suas necessidades de cobrir custos e garantir seu rendimento, com as expectativas e condições de pagamento do cliente.

Bernardi (2007, p.123), destaque que:

Preço é um valor definido para um produto (perspectiva interna), portanto um piso, enquanto valor é o preço que o mercado (perspectiva externa) está disposto a pagar pelo 
benefício percebido, ou seja, o limite. Encontrar, pois, um ponto de equilíbrio entre preço e valor é o principal objetivo da política de preços de uma empresa.

Pode-se perceber que a formação do preço de venda inclui fatores que são externos, como por exemplo o valor percebido pelo cliente. Mas, para formar preço primeiramente é necessário calcular o "piso", cálculo que deve ser feito através dos custos e despesas dispendidos na produção.

Para formar o preço por meio do custo de produção existem diversas maneiras. A formação de preço por intermédio do markup é muito utilizada, por permitir que se insira no preço todos os custos e uma margem, de forma facilitada.

\subsubsection{Markup}

O markup é uma taxa de marcação que é aplicada aos custos do produto, com objetivo de cobrir todos os custos, despesas e uma margem escolhida pelo produtor. O markup é um valor adicionado ao custo, expresso em um percentual do preço de venda (BERNARDI, 2007).

O mark-up é definido por Hoji (2009, p. 371) como "uma taxa predeterminada que se adiciona sobre a base, que pode ser custo total, custo variável, custos e despesas variáveis, custos de matéria-prima, etc., com o objetivo de determinar o preço de venda". O markup pode ser multiplicador ou divisor, porém o preço encontrado será sempre o mesmo. Para facilitar o entendimento o trabalho utilizará o markup divisor.

A fórmula para aplicação do markup divisor é a seguinte:

$\mathrm{PV}=$ Base $/(100 \%-\mathrm{CD} \%-\mathrm{L} \%) / 100$

Onde:

$\mathrm{PV}=$ Preço de Venda

Base $=$ todo custo ou despesa que puder ser apurado unitariamente

$\mathrm{CD} \%=$ Custos e despesas percentuais, que não podem ser apuradas em valor.

$\mathrm{L} \%=$ Lucro percentual que se deseja obter

Considera-se na base todo valor que puder ser apurado em unidades monetárias, de forma unitária. Aquilo que não puder ser apurado na base, deve ser incluído ou nos custos e despesas percentuais ou no lucro percentual. Dessa forma o preço cobrirá todos os custos e despesas e ainda formará uma margem de lucro. 


\section{METODOLOGIA}

Quanto aos objetivos, a pesquisa caracteriza-se como descritiva que de acordo com Silva (2008) é aquela em que o pesquisador descreve e correlaciona as variáveis por meio de técnicas preestabelecidas e padronizadas sem interferir na pesquisa.

Em relação aos procedimentos, trata-se de um estudo de caso, visto que, de acordo com Beuren (2010), tal método pode ser assim entendido pelo fato de ser um estudo concentrado em um único caso, havendo um aprofundamento do conhecimento acerca de determinado caso específico. O presente estudo pode ser caracterizado como estudo de caso por ser desenvolvido no caso específico formação de preço de venda de morangos orgânicos produzidos em uma pequena propriedade rural.

Em relação à abordagem, a pesquisa pode ser considerada como um estudo qualitativo, o qual de acordo com Marconi e Lakatos (2008) permite analisar e interpretar aspectos mais profundos, descrevendo a complexidade do comportamento humano, fornecendo uma análise mais detalhada sobre investigações, que neste estudo permitiu identificar os valores desde o princípio com os investimentos iniciais até a primeira produção.

Quanto aos meios de coleta de dados, todas as informações foram coletadas mediante entrevistas, com a produtora e com proprietário de frutaria. As entrevistas foram feitas de forma semiestruturada, o que permite o levantamento de informações básicas as quais são preestabelecidas para as entrevistas, e ao mesmo tempo permite ao entrevistado fornecer, espontaneamente, outras informações, que a princípio não haviam sido planejadas pelo pesquisador, mas que podem ser fonte de dados importantes ao estudo. As entrevistas foram feitas in loco, na propriedade produtora, e na frutaria, conforme disponibilidade dos entrevistados. A análise dos dados foi realizada por meio do processamento dos dados coletados com base nas informações apresentadas na revisão da literatura sobre o assunto.

\section{RESULTADOS E DISCUSSÃO}

A propriedade estudada está situada em Sede Alvorada/PR, e a proprietária, por trabalhar na cidade, não a utilizava para cultivo. Depois de um tempo, houve a necessidade de incrementar a renda e voltar a atuar como produtora rural. Para isso, procurou alternativas que permitissem um início imediato no cultivo. A opção escolhida pela produtora foi a de morangos orgânicos, por entender que uniria práticas de preservação do meio ambiente, cultivaria produtos saudáveis e de qualidade para serem revendidos. 
Para o cultivo dos morangos, buscou financiamento para a construção de uma estufa de 60 metros x 10 metros, conforme figura 1, aquisição de 6.000 mudas de morango e outros gastos iniciais. $\mathrm{O}$ financiamento será pago em 8 (oito) anos, com juros de $2 \%$ (dois por cento) ao ano.

Os investimentos iniciais para produção totalizam $\mathrm{R} \$ 62.130,00$, porém todos durarão mais de um ano, tendo que ser apurado o valor correspondente à cada ano, conforme detalhado na Tabela 1.

Tabela 1: Investimentos iniciais para produção de morango orgânico

\begin{tabular}{lrrr}
\hline \multicolumn{1}{c}{ Item } & Valor (em R\$) & Vida útil (em anos) & Valor anual (em R\$) \\
\hline Estufa & $57.000,00$ & 10 & $5.700,00$ \\
$\begin{array}{l}\text { Máquina de } \\
\text { pulverização }\end{array}$ & 130,00 & 2 & 65,00 \\
Mudas & $5.000,00$ & 2 & $2.500,00$ \\
\hline Total & $\mathbf{6 2 . 1 3 0 , 0 0}$ & & $\mathbf{8 . 2 6 5 , 0 0}$ \\
\hline
\end{tabular}

Fonte: dados da pesquisa, 2017

Figura 1: Estufa de morangos orgânicos em fases diferentes de produção
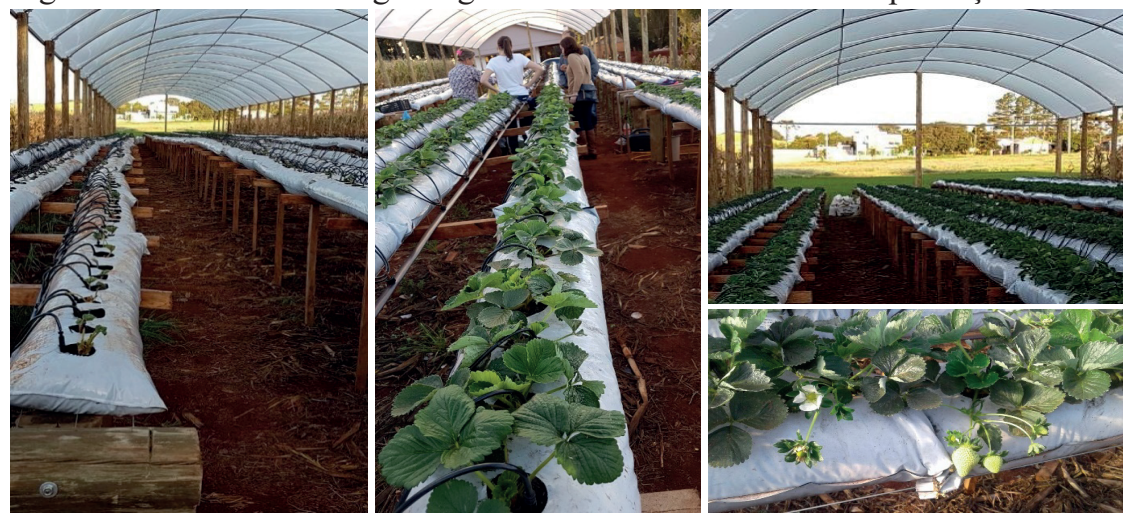

Fonte: dados da pesquisa, 2017

Para se chegar ao custo do morango, separou-se os gastos inicialmente em despesas e custos. E os custos em fixos e variáveis. Os custos variáveis foram apurados conforme tabela 2. Como o morango é uma cultura permanente que produz por 2 (dois) anos, escolheu-se calcular o custo para toda a safra prevista nesses dois anos. Isso se justifica já que o morango produz frequentemente, tendo variações de produção conforme o clima, porém mantendo a média total dos dois anos. A previsão de colheita total em 2 anos é de $8.400 \mathrm{~kg}$. A comercialização é 
feita em bandejas de 200 gramas, que são transportadas em caixas com capacidade para 4 bandejas.

Tabela 2: Custos variáveis por 200 gramas de morango produzido

\begin{tabular}{lc}
\hline \multicolumn{1}{c}{ Item de custo } & Custo por 200 gramas (em R\$) \\
\hline Bandeja & 0,18 \\
Caixa papelão & 0,38 \\
Etiqueta & 0,08 \\
\hline \multicolumn{2}{c}{ TOTAL } \\
\hline
\end{tabular}

Escolheu-se alocar como custos variáveis somente as embalagens, já que o restante dos custos ocorrerá, independentemente da quantidade produzida. A caixa de papelão custa $R \$ 1,50$, porém é utilizada para armazenagem de 4 bandejas, custando por bandeja $\mathrm{R} \$ 0,38$. Os custos variáveis somam o total de $\mathrm{R} \$ 0,64$ para uma bandeja de 200 gramas de morango.

Para totalizar os custos é necessário apurar os custos fixos, conforme demonstrado na tabela 3 .

Tabela 3: Custos fixos por 200 gramas de morango produzido

\begin{tabular}{lrr}
\hline \multicolumn{1}{c}{ Item de custo } & $\begin{array}{c}\text { Total para 2 anos } \\
\text { (em R\$) }\end{array}$ & $\begin{array}{c}\text { Custo por 200 gramas } \\
\text { (em R\$) }\end{array}$ \\
\hline Estufa & $11.400,00$ & 0,27 \\
Mudas & $5.000,00$ & 0,12 \\
Adubo & $5.600,00$ & 0,14 \\
Adubo folhar & $1.800,00$ & 0,04 \\
Água & $2.160,00$ & 0,05 \\
Luz & $3.600,00$ & 0,09 \\
Telefone & $1.200,00$ & 0,03 \\
Máquina pulverizar & 130,00 & 0,01 \\
Mão de obra terceirizada & $25.593,84$ & 0,61 \\
Mão de obra familiar & $72.000,00$ & 1,71 \\
\hline TOTAL & $\mathbf{1 2 8 . 4 8 3 , 8 4}$ & $\mathbf{3 , 0 7}$ \\
\hline
\end{tabular}

Fonte: dados da pesquisa, 2017

Os custos fixos por bandeja de 200 gramas somaram $\mathrm{R} \$ 3,07$, valor 
maior que os custos variáveis. Percebe-se que o valor da estufa é de $\mathrm{R} \$ 0,27$, o que demonstra a necessidade de manter a produtividade, para que seja possível recuperar os investimentos feitos. A mão de obra terceirizada é de 1 (um) funcionário que é contratado para serviços gerais, que ganha um salário mínimo (atualmente R \$ 937,00), e somados ao Funrural de 2,7\% e mais a provisão de $13^{\circ}$ salários e férias, perfaz um gasto mensal de $\mathrm{R} \$ 1.066,41$. O restante da mão de obra necessária é desenvolvido pela proprietária e por familiares em momentos de maior trabalho. Essa mão de obra familiar não é paga efetivamente, mas é necessária para a manutenção da família e foi estimada em R \$3.000,00.

A comercialização do produto é feita somente regionalmente, em panificadoras, mercados ou para consumidor final. As despesas que são necessárias para a comercialização do produto são apenas de transporte, cujo valor é em média R $\$ 0,18$ por bandeja de 200 gramas. A tabela 4 resume a composição dos gastos.

Tabela 4: Gastos totais por 200 gramas de morango produzido

\begin{tabular}{|c|c|}
\hline Item de custo & Custo por 200 gramas (em R\$) \\
\hline Custos variáveis & 0,64 \\
\hline Bandeja & 0,18 \\
\hline Caixa papelão & 0,38 \\
\hline Etiqueta & 0,08 \\
\hline Custos fixos & 3,07 \\
\hline Estufa & 0,27 \\
\hline Mudas & 0,12 \\
\hline Adubo & 0,14 \\
\hline Adubo folhar & 0,04 \\
\hline Água & 0,05 \\
\hline Luz & 0,09 \\
\hline Telefone & 0,03 \\
\hline Máquina pulverizar & 0,01 \\
\hline Mão de obra terceirizada & 0,61 \\
\hline Mão de obra familiar & 1,71 \\
\hline Despesas & 0,18 \\
\hline Transporte & 0,18 \\
\hline TOTAL & 3,89 \\
\hline
\end{tabular}

Fonte: dados da pesquisa, 2017 
O total de gastos para produção e venda de uma bandeja de 200 gramas de morango orgânico é de $\mathrm{R} \$ 3,89$. Todos os custos e despesas já foram inseridos nesse valor gasto por bandeja, portanto para formação do preço por meio do markup só falta incluir a margem de lucro que a proprietária deseja. Como já foi inserido no custo uma remuneração pela mão de obra dela, a margem que ela deseja obter para reinvestimento e para garantia caso houver algum imprevisto com a produção é de $20 \%$.

Relembrando a fórmula do markup divisor, tem-se:

$$
\mathrm{PV}=\text { Base } /(100 \%-\mathrm{CD} \%-\mathrm{L} \%) / 100
$$

Onde:

Base $=$ todo custo ou despesa que puder ser apurado unitariamente $\mathrm{PV}=$ Preço de Venda

$\mathrm{CD} \%=$ Custos e despesas percentuais, que não podem ser apuradas em valor. $\mathrm{L} \%=$ Lucro percentual que se deseja obter

Aplicando aos dados da pesquisa:

$\mathrm{PV}=\mathrm{CUSTO} /(100 \%-20 \%) / 100$

$\mathrm{PV}=3,89 / 0,80$

$\mathbf{P V}=\mathbf{4 , 3 7}$

Com base no markup se o preço de venda da bandeja de morango orgânico de 200 gramas for fixado em $\mathrm{R} \$ 4,37$ será o suficiente para cobrir todos os custos e despesas, remunerando a mão de obra da produtora, e ainda tendo uma margem de $20 \%$ para qualquer eventualidade.

Para analisar se o preço de venda está compatível com o que está sendo comercializado no município de Cascavel/PR, foi entrevistado o proprietário de uma frutaria que comercializa morangos orgânicos. Atualmente, ele comercializa esse produto eventualmente, devido à dificuldade de compra. Ele compra de um produtor no estado de São Paulo, e paga R \$ 6,50 na bandeja de 200 gramas. Desse valor pago, aproximadamente $\mathrm{R} \$ 0,90$ é referente ao transporte. $\mathrm{O}$ valor de revenda ao consumidor final é de $\mathrm{R} \$ 12,00$ a bandeja. Conforme o proprietário ele consegue vender tudo que adquire, e na sua visão os impedimentos para vender ainda mais são o preço e a aparência do produto.

A qualidade do produto na primeira safra foi ótima segundo a produtora, como pode ser verificado na figura 2. Apesar da aparência ser sempre uma preocupação sobre o produto orgânico essa foi uma hipótese rejeitada nesse caso. A aparência do produto tem sido um motivador das vendas.

Comparando o valor pago pela frutaria ao produtor de São Paulo, e o 
preço de venda calculado para a produção de morango na agricultura familiar na região, percebe-se uma diferença de $\mathrm{R} \$ 2,13$, da qual $\mathrm{R} \$ 0,90$ é correspondente a transporte. Isso mostra não somente a viabilidade da produção, como a importância de estabelecer circuitos mais curtos de compra. Nesse caso, pode-se não somente vender sem frete para as frutarias, mas também realizar a venda direta ao consumidor.

Figura 2: Morangos orgânicos
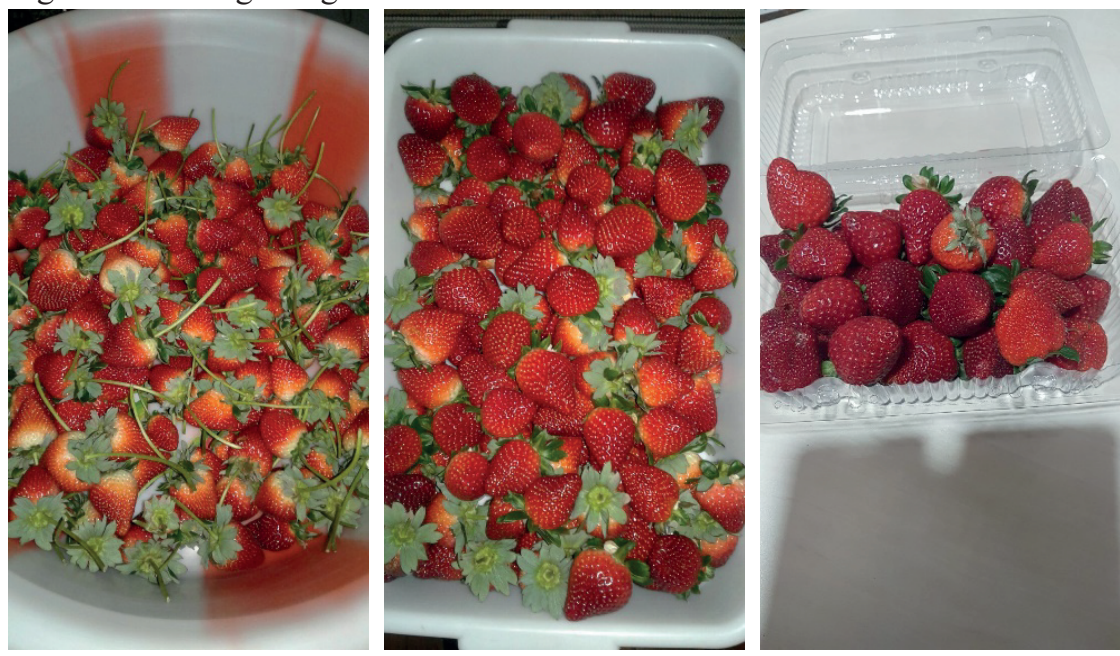

Fonte: dados da pesquisa, 2017

\section{CONSIDERAÇÕES FINAIS}

A produção de orgânicos tem crescido por oferecer uma alternativa de diferenciação para os agricultores familiares. A necessidade dos produtores e consumidores de preservarem o meio ambiente e levarem uma vida mais saudável tem sido um impulsionador para esse tipo de produção.

Para que o produtor não incorra em prejuízos, é necessário conhecer seus custos e formar o preço de venda corretamente. Foi possível utilizar alguns conceitos da contabilidade de custos, contabilidade rural e formação de preço de venda através de markup para calcular o custo da produção e formar o preço do morango orgânico. Algumas adaptações foram necessárias por conta da particularidade da agricultura familiar, em específico o fato da mão de obra familiar e ser remunerada informalmente, não sendo detalhado o salário individual e sim de forma coletiva, visto o trabalho executado em família como é o costume na agricultura familiar. Mas, para isso foi calculado um valor destinado para a ma- 
nutenção da família.

Após o cálculo do custo e preço de venda, que chegou em $\mathrm{R} \$ 4,37$ para uma bandeja de 200 gramas, foi possível comparar com o preço praticado no município de Cascavel/PR. Foi percebido que o produto apresenta um preço menor, e ainda por cima evita os gastos com frete para trazer produto de outros estados brasileiros, oferecendo oportunidade de acesso aos produtores e consumidores no mercado local.

\section{REFERÊNCIAS}

BERNARDI, L. A. Manual de Formação de preços: políticas, estratégias e fundamentos. 3 ed. São Paulo: Atlas, 2007.

BITTENCOURT, G. Agricultura Familiar e Agronegócio - Questões para Pesquisa. Brasília. CNPQ. 2002. In: LIMA, D. M. de A.; WILKINSON, J. (org.) Inovações nas tradições da Agricultura Familiar. Brasília: CNPq/Paralelo 15, 2002, p. 85-94.

CREPALDI, S. A. Contabilidade Rural: Uma Abordagem Decisorial. 7. ed. São Paulo: Atlas, 2012.

FONSECA, M. F.; WILKINSON, J. As oportunidades e os desafios da agricultura orgânica. In: LIMA, D. M. de A.; WILKINSON, J. (org.) Inovações nas tradições da Agricultura Familiar. Brasília: CNPq/Paralelo 15, 2002, p. 249-280.

HOJI, M. Administração financeira e orçamentária: matemática financeira aplicada, estratégias financeiras, orçamento empresarial. 8. ed. São Paulo: Atlas, 2009.

MARION, J. C. Contabilidade Rural. 13. ed. São Paulo: Atlas, 2012.

MARTINS, E. Contabilidade de Custos. 9. ed. São Paulo: Atlas, 2003.

ORSI, S. Principais contribuições do Programa de Apoio às Tecnologias Apropriadas - PTA ao Programa de Verticalização da Pequena Produção Agrícola do Distrito Federal -

PROVE. In: LIMA, D. M. de A.; WILKINSON, J. (org.) Inovações nas tradições da Agricultura Familiar. Brasília: CNPq/Paralelo 15, 2002, p. 155-168. 